\title{
Disguised compliance or undisguised nonsense? A critical discourse analysis of compliance and resistance in social work practice.
}

\begin{abstract}
This article examines how the term disguised compliance first emerged and developed into the popular catchphrase that is used in practice today. Using critical discourse analysis, we explore how language affects practice and how social workers draw on a predetermined concept to rationalise concerns relating to parental resistance. We contend that concepts such as disguised compliance are misleading as they do not improve social workers' abilities in detecting resistance or compliance. Instead, we argue that social workers should be cautious when using popular mantras which on the surface appear effective in describing parents' behaviours but, in reality, conceal concerns relating to risk, accountability and blame. This study differs from the current literature which advocates social workers should be aware of disguised compliance by shifting the emphasis away from the behaviours of parents and towards acknowledging the power such discursive activities can have on practice.
\end{abstract}

Keywords: Disguised compliance; resistance; affect; discourse; risk; accountability 


\section{Introduction}

In recent years, high profile cases of child abuse have provoked strong reactions from the public with regard to the role social workers have played. This is only natural given that when a child dies, people want to know who is responsible, who is going to take the blame and what measures can be implemented so that similar situations are prevented from occurring again in future (Leigh, 2017; Lonne and Parton, 2014). Questions of accountability and prevention, therefore, play an integral part in the social construction process of understanding what happened in order that lessons can be learned and future tragedies can be avoided. This process of deconstructing what happened always takes place after a crisis unfolds and is an aspect of how societies at large react after a tragedy has occurred (von Scheve et al. 2014).

In England, one social construction process which takes place after a child has been seriously harmed or died is the Serious Case Review (SCR). SCRs are locally conducted multi-agency reviews which aim to explore the circumstances which led up to the abuse or neglect of the child concerned. One key theme that has arisen from the multi analysis of SCR reports is the behaviour of parents and carers, particularly the way in which they have been able to dupe professionals into believing they are engaging with social work intervention when in reality they have no intention of doing so (see Disguised Compliance Factsheet, NSPCC, 2014).

The challenges of working with families who appear to resistant to receiving support or intervention is an area of social work which has been considered from a wide range of perspectives within research and literature (see Ferguson, 2009; Gibson, 2015; Shemmings et al., 2012; Turnell, 2006; Turney, 2012). In sociological literature, it has also been widely recognised that professionals who are deemed responsible for a particular crisis in which a 
child has been harmed are significantly affected by the courses of action that follow the tragedy. The detailed accounts of, for example, Peter Connelly's suffering were known to have had a profound reach, far beyond the social work community and into the sphere of politics (Jones, 2015; Shoesmith, 2016; Warner, 2013). But what is particularly important to acknowledge in this context is how subsequent responses to such a tragedy discretely shape the ways future practices are then developed. One underdeveloped area in social work research and practice, in particular, is considering how discourse affects social interactions between social care professionals and parents (Lonne and Parton, 2014). The impact discourse can have on practice has not, however, escaped the attention of the entire social work community.

Recently, Kettle and Jackson (2017) commented on the way in which the 'rule of optimism' has been used over the years and, as a result, has acquired considerable currency. The context in which the 'rule of optimism' has explicitly gained most influence is in SCRs because it has proved to be a useful tool for explaining the details of perceived professional naivety, inaction, imprudence and poor decision making (Kettle and Jackson, 2017). Yet, Robert Dingwall (2013) one of the authors who introduced the 'rule of optimism' into social work (see Dingwall et al. 1983) has argued that the way the term has been applied to practice situations has been incorrect. Subsequently, it has deviated considerably from its original definition which was initially developed to describe how the complex, structural constraints within organisations affected the way in which social care institutions responded to practice situations. What Dingwall and colleagues had never intended, nor expected, was that the term would then go onto be used as a tool to blame social workers for situations where a child had been seriously harmed or had died.

The rule of optimism is not the only social work term to have faced criticism. In 2017, Paul Hart, a family law barrister, expressed concerns about another popular catchphrase in a 
short article he wrote for the Family Law website entitled 'Disguised compliance or undisguised nonsense?' Hart admitted that he was used to reading statements that discussed parents' responses to the direct work local authorities had required them to complete, however, what had piqued his interest, was the way in which some social workers inferred that parents' actions were symptomatic of disguised compliance. Thus, professionals contended that parents were not genuinely working towards making the required changes but rather, undertaking the work to give a false impression they were cooperating with the specified objectives.

Hart noticed two things in particular. First, although the term was being applied to the concept of parental resistance (when parents do not comply with what is being required of them to effect change) the words 'disguised compliance' were ineffectively describing that which was being implied. Thus, although the term was being used to articulate concerns about 'non-compliance' or 'resistance', when broken down into two distinct separate words, it actually meant 'concealed agreement'. Yet, Hart realised that it was highly unlikely that parents would hide their agreement with a social care plan, but rather more likely that parents would try and hide their disagreement with a plan. Therefore, instead of using 'disguised compliance' to label parents who were doing what was required, technically social workers should have been using the term 'disguised resistance' or 'disguised non-compliance' to describe concerns they held that parents were not in agreement with the decided plan or intervention.

Second, Hart found that 'disguised compliance' was often being used as a diagnostic label, one which misled rather than helped the social worker. Hart used the phrase 'diagnostic' in particular because he found that every time 'disguised compliance' was applied to a parent it was accompanied by a list of typical symptoms which attempted to define how their behaviour had met the criteria of suspected resistance. This diagnosis, 
however, overlooked the fact that most parents struggled to meet all expectations smoothly because many were lengthy, contradictory and difficult to achieve consecutively in a short period of time. Although 'disguised compliance' appeared to be a helpful term for professionals in that in enabled them to express concerns about parental behaviour, in contrast, parents found it far from helpful. Being labelled with 'disguised compliance' not only increased their worry and anxiety but it left parents feeling they were being set up to fail.

The purpose of this paper, therefore, is to further explore some of the assertions that Hart (2017) made by doing three things. First, we aim to explore the origins and longevity of the term 'disguised compliance', namely, why, and how, the term was inaugurated into social work literature. Second, using a critical discourse analysis (CDA) approach, we analyse how the term became established in social work discourse and third, we discuss how disguised compliance has been used in social work practice.

Our main objective is to explore how the concept has affected the social work community. Using selected extracts as exemplars from our findings, our analysis attempts to illustrate how discursive concepts can be linked to patterns of affect, thought and action. We will conclude that if social workers want to effectively engage in and develop relationships with families to improve their practice then the use of popular colloquialisms needs to be reevaluated. We will argue that although familiar mantras may on the surface appear helpful in describing parents' behaviours, in reality, they are only successful in doing one thing: concealing the wider issues involved when professionals work with risk.

\section{The history of disguised compliance}

Sometimes, during cycles of intermittent closure, a professional worker would decide to adopt a more controlling stance. However, this was defused by apparent co-operation from the family. We have called this disguised compliance because its effect was to neutralize the 
professional's authority and return the relationship to closure and the previous status quo (Reder et al, 1993, pp 106-7).

The first time the term 'disguised compliance' was used in social work literature was in 1993 in the book Beyond Blame. The authors (a psychiatrist, a psychologist and a social worker) used the book to try and make sense of, and summarise, all the major child abuse inquiries that had occurred in England since 1973. In reviewing and analysing, in total, 35 inquiries, they attempted to identify common themes between the different cases, focusing particularly on the interactions that took place between parents and professionals. The purpose of doing this exercise was to provide practitioners with tips on what they could look for when working with cases of suspected abuse so they could prevent future tragedies from occurring.

As the quote at the start of this section highlights, disguised compliance emerged as a term which the authors felt was effective in describing the way a family would respond once a practitioner adopted a more controlling stance. The examples Reder et al. (1993) gave of how this action played out in practice were as follows: a sudden increase in school attendance; attending a run of appointments; engaging with professionals such as health workers for a limited period of time; cleaning the house before receiving a visit from a professional.

It is important to note that these examples are often cited as evidence of disguised compliance in the literature we have read and also relate to the list of 'symptoms' that Hart (2017) stated regularly accompanied social workers' diagnostic rationale that parents were not truly being compliant. However, what is also significant in this context is that Reder and colleagues also declared that their research had highlighted an anomaly. They had discovered that alongside the theme of disguised compliance a puzzling pattern of 'prediction' had emerged (Reder et al.1993: 131). This meant that despite reading 35 inquiry reports, the authors had found that it was impossible to predict which families would disengage from or 
resist social work intervention. And what they found even more baffling was that it was impossible to determine whether this form of disengagement or resistance actually increased the likelihood of the child being killed.

Although the complexity of this anomaly was discussed in detail by the authors as a potential limitation of their approach, it was not the main feature of the book that was subsequently taken forward. Instead, once the text was published, the finding that appeared to catch the social work community's interest the most was the notion of 'disguised compliance'. Perhaps this was because the term succinctly captured the idea that families could, and would, pretend to comply with social workers, and that resistance of this kind arose at a time when concerns relating to parental deceit were increasing. Whatever the reason may have been, what is known is that disguised compliance not only grew in popularity but it also became a regular feature of a number of serious case reviews, government reports, academic articles, factsheets relating to child abuse and social work blogs.

\section{Social work practice and discourse}

The National Society for the Prevention of Cruelty to Children (NSPCC) is one organisation which has embraced the use of disguised compliance. Drawing on the findings of a wide range of SCRs, it has created factsheets designed to improve multi-agency practice at all levels. The NSPCC states, on its own website, that it is the leading children's charity in the UK, Channel Islands and Isle of Man and that its primary aim is to end child abuse. By employing the term 'disguised compliance' in its publications, it has attempted to help practitioners understand parental resistance by using SCR findings to highlight when and how parents have been manipulative. These factsheets have inspired a number of social work professionals (such as trainers and consultants) and organisations (local authorities) to run 
'disguised compliance' workshops for social workers so that they can be alert to signs of abuse and neglect (see for example Hall, 2017).

The idea that there may have been a common theme across cases in which parents or carers have deceived professionals is a concept which appears to have appealed to many. In 2003, Lord Laming's inquiry report into the death of Victoria Climbie called for professionals to adopt a form of 'respectful uncertainty' as he found that social workers had been misinformed and manipulated by Victoria's carers. The death of Peter Connolly, five years later, was cited as further evidence that social workers had remained 'over optimistic' and 'too trusting' (Laming cited in Easton 2009). Yet, in a similar vein to Dingwall et al. (1993), Turney (2012) has proposed that making the right decisions in practice is not always a straightforward process because social workers are frequently required to act in emotionally fraught situations with limited and fragmented information. Knowing, therefore, whose story to trust and whose claims for recognition are valid, is an aspect of social work that is difficult to ascertain as there is 'no foolproof way of always getting it right' (Turney, 2012: 154).

Ultimately, what appears to matter most, is that social workers recognize their limitations in certain situations and focus instead on what they can achieve.

\section{Affective framing in discourse analysis}

Sociologists have argued for some time that if researchers are to demonstrate how behaviourism and interactionism are intimately connected then they need to consider how the essential conditions for social action are affectively perceived (von Scheve et al. 2013). In order to further understand how disguised compliance has affected the social work community, we will utilise the concept of 'affective framings' alongside discourse analysis to explore how groups are impacted by aspects of discourse and how this can then influence intuitive and pre-reflexive social actions (see Wetherell, 2012). 
Affect is a psycho-social concept which surfaces in every text, either directly or discretely (Gabriel, 2015). Thus words, and the way they are used, have the ability to generate a variety of affective currents, such as nostalgia, anger, bliss, disgust and envy. Affective framings often emerge in complex constellations, whereby one affective current, such as shame merges with or gets neutralized and silenced by a different one, such as pride (Gabriel, 2015). The act of analysing affective processes has often been challenged because it is felt that analysts do not always ensure they separate their own views from the extract of text that is under investigation (Wetherell, 2012).

Although it is recognised that drawing on affect can be problematic in some instances (see Wetherell, 2012), its importance has been reflected in recent studies which have attended to the complex links between media framings, shame and blame in social work practice (see Leigh, 2017; Gibson, 2015). Getting it wrong or being held accountable for mistakes can lead social workers to being judged as inferior or inadequate and in turn induce personal feelings of shame and guilt (Gibson, 2015). Examining affective framings in discourse therefore enables researchers to bring into play the atmospheric factors which impacted on those who originally wrote the documents. This process can help readers understand how these authors were moved, attracted to or pained by certain social interactions.

\section{Methodology and theoretical framework}

Although the term 'disguised compliance' was first introduced in 1993, its growing popularity has meant that it is likely that its form and frequency has been re-contextualised over the years. If the original definition by Reder et al. (1993) has, therefore, been recycled and reconditioned to address the ongoing developments and challenges that social workers face in relation to parental resistance then Richardson \& Wodak (2009) suggest researchers need to use a wide range of materials if the discourse in practice is to be understood properly. 
In order for us to explore how disguised compliance was created by, and creates social understandings, we adopted a critical discourse analysis (CDA) approach and following Reisigl and Wodak's (2001) advice we chose to focus on three specific areas: 1) texts 2) discursive practices of production and consumption and 3) on the wider socio - cultural practices which help reproduce a discourse. We took discourse to mean the practical (formal and informal) realm of language in action (see Wetherell, 2012).

We began our search by keying the term 'disguised compliance' into the University of Sheffield Journal Database, GoogleScholar and Google and found in total 68 documents. They were all UK specific and included: journal articles or books, Serious Case Reviews, Reports on Serious Case Reviews, Factsheets, Safeguarding in Schools reports, Safeguarding Children Board reports and social work or family law blogs. The organisation which has used the term most frequently is the NSPCC. Our search led to a total of 43 articles which came directly from their website. These articles consisted of NSPCC Factsheets; Learning from Case review Briefings; Biennial reviews of SCRs as well as SCRs which had been published by NSPCC and which had used the term 'disguised compliance', all of which were stored on the NSPCC National Case Review Repository.

Our analysis of the selected texts involved looking at the form, content and function of the text, starting with - analysis of vocabulary and semantics, grammar of sentences, the textual organisation and so on (Fairclough, 1995). As well as being socially conditioned, discourse also has an active element in that it represents situations, creates social identities and defines how people interact with one another (see Crossley and Leigh, 2016). We needed to, therefore, consider not only how disguised compliance appeared in a text but also how it affected the situations in which it was being used and for what purpose. In order for us to carry out a rounded analysis, we examined socio-cultural practices as well to see if there were 
any concerns raised in relation to power, especially when used in practice in certain circumstances (see Fairclough, 2010).

Drawing on Reisigl and Wodak's (2001: 44) CDA framework, we focused on five questions which helped us to deconstruct the documents which used 'disguised compliance' so that we could understand why particular events occurred:

1) Referential Strategies: How are people named and referred to semiotically?

2) Predicational Strategies: How are these people described? What qualities or characteristics are attributed to them?

3) Argumentation: What arguments (explicit and/or implicit) are used to support these characterisations, and/or justify exploiting and discriminating against others?

4) Perspectivisation: From whose perspective are such namings, descriptions and arguments expressed?

5) Intensification and mitigation: Are these utterances stated explicitly or implicitly? Are they intensified or mitigated?

A limitation of the CDA approach is that, as former practising social workers, we recognised our own views could influence the way in which the texts have been interpreted. To remain critically aware, therefore, we used Riesigl and Wodak's (2001) five strategy questions to help us detect and scrutinise discrepancies and contradictions from within a wide range of reports. Furthermore, we have used the CDA framework as a way of structuring the following discussion.

The problem with the term 'disguised compliance'

Referential strategies: How are people named and referred to semiotically? 
Reisigl and Wodak (2001) suggested that by naming people, we construct and represent social actors from a particular in-group or outgroup. This can be done in a number of ways and includes membership categorisation devices, reference to cultural tropes, depersonalisation metaphors and metonymies. We found that 'disguised compliance' was often used in literature such as serious case reviews where authors were examining the facts of a particular case in an attempt to understand what had happened and why, so that future learning could be achieved. For example:

Apparent or disguised cooperation from parents often prevented or delayed understanding of the severity of harm to the child and cases drifted. Where parents ...engineered the focus away from allegations of harm, children went unseen and unheard (Brandon et al, 2008a).

That [the LSCB] review its model of reflective supervision, to ensure that it is fit for purpose in assisting professionals to gain confidence in working with parents who are manipulative and show disguised compliance (Sidebotham et al. 2016: 227).

In both these extracts, the group identified as being most likely to display signs of 'disguised compliance' are parents. Reisigl and Wodak (2001) have argued that in examining the ways that people are named or labelled, subtler forms of discrimination are subsequently revealed. Thus, referential strategies manifest the imprint of predication as in this context they affirm that parents are most likely to be 'manipulative and show disguised compliance' and in turn, be the ones who actively deceive and dupe the professional (Sidebotham et al. 2016: 227).

However, although this may appear to be the case in SCR reports, care needs to be taken to ensure that this label is not applied to all families as serious injury or death to a child is relatively rare when the total population of people known to child protection services is considered (Lonne and Parton, 2014). In addition, using 'disguised compliance' so that practitioners can learn from the past, can generate the view that all parents who do not engage cannot be trusted. Other authors have suggested that there may be good reason for why parents do not always respond well to professionals, especially when a professional's 
approach is seen as authoritarian. Featherstone et al. (2014) found, for example, that parents often felt unable to express their views and felt blackmailed into co-operating with a plan they may not have agreed with. Whereas Smithson and Gibson (2016: 569) found that parents felt prejudged by their social worker and were, therefore, less likely to engage in the intervention. Indeed, one of the parents in their study said: 'I'm scared to do or say [anything] and if she says I've got to do something, I'm scared to challenge it in case I'm seen as uncooperative'. The messages to emerge from these studies support Turney's (2012) argument, that if practitioners are to ethically engage with involuntary clients in cases where it is deemed a child is at risk of harm, then they need to begin by building relationships based on recognition, respect and reciprocity.

\section{Predicational strategies: How are these people described? What qualities or characteristics are attributed to them?}

By examining the way in which a particular group is labelled, discourse analysis enables us to document how labels are used to define particular traits, characteristics, qualities and features of actors (Reisigl and Wodak, 2001: 44). This next extract provides an example of how the characteristics of such a group can be further scrutinized:

Then there is the atmosphere that arises within relationships where the parents and carers seem co-operative, but it turns out to be 'disguised compliance' (Reder et al. 1993) and a front for child abuse. Here, another kind of immobilization seems to occur where the worker internalizes the feelings of passivity and helplessness that are projected into him/her, classically in high-risk cases by mothers who are overwhelmed by their own feelings of rage and sense of inadequacy as parents and by the abuse they and their children are experiencing at the hands of (often hidden) men (Ferguson, 2009:476).

It is important to highlight that in this context Ferguson (2009) was attempting to focus on the complex aspects of practice that social workers face in cases which have ended in tragedy. In doing so, Ferguson has identified how social workers often found it difficult to get 
into homes of the families they were working with and when they did, how they found inspecting the home conditions 'a very challenging and uncomfortable thing to do' (2009: 472). In order to explain how social workers encountered barriers when faced with hostility and violence from parents, Ferguson employed the term 'disguised compliance' to explore social workers' reactions in three high profile child abuse inquiries: Victoria Climbie, Peter Connolly and Jasmine Beckford.

As a result, two significant points emerge from Ferguson's (2009) work. The first is that although the term 'disguised compliance' has been taken from Reder et al. (1993), its application has shifted from its original definition. Rather than using the original definition, professionals adopting a controlling stance with a family which is behaving inconsistently, the term is used by Ferguson (2009) to describe how social workers can internalise feelings of passivity and helplessness. This change mirrors the 'recycling' process that Richardson and Wodak (2009) refer to as it demonstrates how language can be reconditioned to address particular challenges or developments in practice.

The second point of interest is the way in which gender has been assigned to a particular group, believed to display the characteristics of 'disguised compliance'. Reisigl and Wodak (2001: 46) have argued that examining the ways in which people are named is helpful in exploring the subtler forms of 'constructing, identifying or hiding social actors'. In this context, the projections, that Ferguson (2009) refers to, have been specifically linked to women from three high profile case who had abused the children in their care. Although the extract assigns ultimate culpability to an absent person- an abusive father- it is through his absence that the mother is made morally circumspect due to her 'projection'.

The identification of mothers as the main parent to display 'disguised compliance' was also a common feature in the other literature we read. Although in most of these cases 
there were fathers present, they were not always identified when issues relating to noncompliance were highlighted:

Mother displayed disguised compliance. On the surface, she appeared to be cooperative, but actually she did not co-operate and was highly avoidant. (Plunkett, 2018:12)

There appeared to be no professional curiosity as to why the appointments were not kept by Ms W and there has been no evidence found whilst conducting this review that professionals considered the significance of these missed appointments, or that this may have been disguised compliance (Duncan, 2017:9).

5.1.2 Examples of parental avoidant behaviour or 'disguised compliance:'

Mother's apparent 'agreement' in July 2014 at the nursery and subsequent failure to follow up the GP referral to the Paediatric Clinic later that month

Mother's agreement then failure to follow up and use the two sources of advice about nutrition / diet

Deceptive reassurances in December 2014 that mother had reversed her negative stance and would accept health visiting support and advice (Smith, 2018:12).

Reddy (2001) has argued that emotional expression is often organised through affective and emotive activities. Affect and emotion can surface in every text, either directly or discretely, because of the way in which words are used (Gabriel, 2015). Ferguson's (2009) example boldly attempts to examine aspects of manipulation and deceit, contentious characteristics that were known to be prominent in three high profile contexts in which the children referred to were known to have lived and died. These are the kinds of cases which can evoke powerful emotions and as demonstrated, Ferguson is not the only author to have been affected. All of the extracts above are taken from contexts in which the authors have been immersed in and had to focus on understanding why serious harm or death has occurred. Yet what is apparent is the way in which 'disguised compliance' has been applied to inadvertently position men and women differentially. 


\section{Argumentation strategies: What arguments (explicit and/or implicit) are used to}

support these characterisations, and/or justify exploiting and discriminating against

\section{others?}

In critical discourse analysis (CDA), although words initially appear to have arbitrary meanings (referential), once these words are attached to particular meanings they become fixed in a particular relationship and are drawn on in future expressions (predicational). As we have demonstrated, the term 'disguised compliance' connotes a general meaning with some variations in its use. This constructs a range of meanings which revolve around the concepts of manipulation and resistance. As a result, it is a term which is able to establish itself as a discursive activity, one which enables all users to talk to one another by exchanging the same currency of concepts (Burr, 2003).

The argumentation strategy in CDA uses the concept of topoi to explain how positive and negative attributions can be justified in language use. Reisigl and Wodak (2001) define topoi as content-related warrants or conclusion rules which connect an argument or arguments to a particular conclusion or standpoint. Topoi are, therefore, often used to connect generalised key ideas to specific statements in order for arguments to be generated.

Thus, in this context, the topoi 'disguised compliance' was originally developed by Reder et al. (1993) to connect the idea that some parents appeared to only co-operate with social workers this only occurred once the practitioner raised concerns about their engagement. In order to explore the argumentation strategy further, we draw on Wilkins (2017) article, We need to rethink our approach to disguised compliance, to demonstrate how this can play out in practice. The extract below is taken from a supervision Wilkins has observed take place between a social worker and his deputy team manager:

Social worker: I saw her last week and we talked about what might happen at the next conference. I was trying to focus on strengths, on what's going well, because I think mum is used to professionals talking at her all the time about what's going wrong or how worried they are and that must be hard for her. 
Deputy team manager: I hear some reservation in your voice.

Social worker: Well, being strengths-focused is obviously a good thing, but how can I know if things are really getting better or if this is just because mum is worried about the plan? Maybe he's going to school and doing well now but if we close the case, I don't know if she really believes in all of this.

Deputy team manager: You're worried about disguised compliance?

Social worker Yeah, like when she knows I'm visiting, she tidies and cleans the house a bit. But she's only doing that because I'm coming around.

This example echoes Hart's (2017) earlier comments and demonstrates how in practice social workers can develop concerns that relate to when a parent complies with a plan and improvements are being made. The social worker's implicit concern, in this context, is that when the mother knows he is visiting she tidies and cleans the house. He therefore suspects that at all other times the house remains messy and dirty, and that motivation to tidy is only triggered by his visit. However, what is not acknowledged, in either the supervision or the factsheet, is how the nature of this action is more akin to a performance, to making a good impression to a professional with power, than it is to disguised compliance. One way of thinking about an individual's performance in more detail is to draw on Goffman's observations of dramaturgy and in particular, stage management.

Goffman (1959) made it clear that when establishing where performances take place, one needs to clarify the context in order to understand why a certain performance is being delivered at that time. Goffman recognised that performances could be deceptive but that making a good impression was an activity that the majority of society engaged in. Thus, there are many people who will tidy their house when they know a visitor is coming. The important difference is that not all people who tidy their home before a visitor arrives are accused of concealing something.

Another way of thinking about this is considering the kind of activity that is taking place between the social worker and the professional. The term 'situated activity' was first 
coined by Goffman (1961: 96) when trying to describe the everyday features of affect in his seminal work on interaction rituals and encounters. He defined 'situated activity' as a somewhat closed, self-compensating circuit of independent actions because he noticed that moments of affective action took place between actors when something distinct or recognisable happened.

Situated affective activity requires formative background conditions that are social, material and spatial as well as physiological. In this example, the situated aspect of this interaction is in the context of a child abuse investigation, where the two actors- social worker and parent- are entered into unequal power relations and morally-laden roles. The tidy home made the social worker feel uncomfortable and cautious, most likely because the features of this particular activity reminded him of 'disguised compliance' and concerned him that he was being deceived.

Furthermore, by voicing his concerns in supervision the social worker appeared to rhetorically infer that if he stopped visiting then the apparent improvements would come to an end. This affective episode was instantly recognised and related to by the supervisor who used the term 'disguised compliance' to diagnose and label the social worker's fears. Yet, as Wilkins (2017) pointed out, by drawing on disguised compliance and focusing on the behaviour of the parent, both the supervisor and the social worker have failed to address what the practitioner may be doing to increase the parent's resistance as well as what he could do to overcome it.

\section{Perspectivisation: From whose perspective are such namings, descriptions and arguments expressed?}


Perspectivisation is an important strategy when considering 'who' has been named, described and used arguments connected to disguised compliance as it helps to understand the way in which arguments are presented. Reisigl and Wodak (2001) suggest that this stage of discourse analysis can benefit from focusing on the perspective of the author, the ways in which speakers express or conceal their involvement in discourse.

The texts that we have predominantly drawn on share a few common features in that they are trying to understand features of parents' behaviours, therefore mainly focused on social work practice, the findings from serious case reviews or situations where children have been harmed or died (Brandon et al, 2008a; Duncan, 2017; Ferguson, 2009; Plunkett, 2018; Reder et al. 1993; Sidebotham et al. 2016; Smith, 2018). The outcomes of these texts have been later used to inform research, factsheets, safeguarding reports or social work blogs, developed with the intention of helping practitioners become aware of what they need to be alert to in order to prevent child abuse from occurring.

The authors of SCR reports have been tasked with the objective of finding out why children have died so that social workers can learn from the past and prevent children from being harmed in the future. They will have read a large number of accounts, which would have detailed the circumstances and suffering that children will have encountered. Undertaking such meaning- making exercises requires analysis, translation and processing, activities which inevitably produce embodied affective responses. Some authors even admitted within their report that this process involved powerful and painful reading which affected them significantly (Brandon et al. 2008). The majority also acknowledge that the complexity of family circumstances meant that it was not always possible to predict with hindsight what the outcome for most of the children would have been. A statement that supports Reder et al's. (1993) original claim that it was impossible to predict which families 
would disengage from or resist social work intervention, and whether either action actually led to increased or decreased risk to the child.

\section{Intensification and mitigation: Are utterances stated explicitly or implicitly? Are they intensified or mitigated?}

Fifth and finally, critical discourse analysis should examine strategies of intensification and mitigation. In spoken discourse these can be enacted through emphasising particular words, using forms of expression, by mitigating and attenuating particles to sharpen or tone down its ideational content and, in so doing, help construct a particular identity for the group in question (Reisigl \& Wodak, 2001: 83).

Disguised or partial parental compliance also wrong-footed professionals.... (Brandon et al, 2008: 89- 90) [own emphasis added]

At each of these transitional points, there is the danger of 'start again syndrome'..... a risk that professional optimism along with disguised compliance, can again delay professionals in making an accurate assessment of the risk to a child or slow the chances of a successful intervention (Hall, 2017) [own emphasis added].

Potter and Wetherell (1995) contended that people use the resources that are available to them to make evaluations, construct factual versions and perform particular actions. These two examples demonstrate that rather than accept that there is 'no foolproof way of always getting it right' (Turney, 2012: 154), professionals who are deemed naïve or able to be deceived, are labelled as those who focus on the positives. These are the 'over optimistic' 
practitioners who are at risk of being manipulated by the parent, the same ones who fail to spot the signs of disguised compliance.

The use of intensification strategies adds to the constructed events which mark out everyday language practices and intensify the groups of meanings and identities assigned to both social workers and parents (see Gabriel, 2015; von Scheve et al. 2014; Wetherell, 2012). They can be used to fend off external criticism or maintain a credible stance in a given interaction all dependant on the context in hand. Yet if we acknowledge that intensification and mitigation strategies also highlight language as a site of variability, then we must also consider it an activity that involves disagreement and potential conflicting meanings (Burr, 2003). And in social work, conflict inevitably leads to discussions which relate to power relations and arise from written accounts which use the concept of 'disguised compliance' to identify the foolish professional and the manipulative parent.

This characterisation is often present in SCRs, where the rhetorical impact of the term can be used in the context of hindsight to retrospectively blame the social worker for not being discerning enough to 'see through' parental fabrications. By labelling the lying of parents, in these extreme cases, as 'disguised compliance', a diagnostic label is used as a professional gambit which not only acts to identify the social worker's inability to detect the parent's manipulation but also constructs a valid argument that her failure to do so is a reasonable expectation of her expertise.

\section{Disguised compliance or undisguised nonsense?}

In this discussion, we now turn to examine the consequences of critically analysing the term 'disguised compliance' and explore the implications our findings may have on practice. This study contributes to the fields of social work and sociology in many ways. First, despite Reder et al.'s (1993) theory of disguised compliance being written 25 years ago, it is evident 
that their concept still has a significant impact on social work policy and practice. It has influenced a wide range of authors, from academics, to policy makers, to social work bloggers and safeguarding consultants and, as a result, has developed into a concept which is used to explain the behaviours of parents and carers in a variety of different contexts.

Our analysis of these texts has demonstrated that authors who draw on the term do so in an attempt to explain how practitioners have missed signs of resistance. Child protection social work is known to be a difficult task. Practitioners are required to work sensitively between families' rights to privacy in the home and the fact that, in some cases, homes can be potentially dangerous places. When social workers enter these private domains, they may engender feelings of 'disgust and fears for their own bodily integrity and well-being' (Ferguson, 2004: 476). Some have suggested that these encounters are saturated with anxiety and judgment and as a result, the breaching of the home environment is made easier when families are 'othered' in some way (Keddell, 2014; Scourfield \& Welsh, 2003).

However, rather than binary roles emerging which position parents as either resistant or compliant, the term 'disguised compliance' is often employed to remind social workers that they should never be too trusting or too optimistic, they should instead be suspicious of everyone they work with. Unfortunately, this form of suspicion is not without consequence and this leads to the second contribution of this article which extends on the literature exploring language use in social work.

Returning to the argument presented by Kettle and Jackson (2017) that the 'rule of optimism' is often misused in talk and text, we have found evidence which demonstrates that the term 'disguised compliance' is also vague and potentially interprets parental behaviour in a suspicious and negative manner. There have been several instances where it has been recycled to describe how social workers feel in hostile situations or used to identify the gender of the group most likely to display signs of non-compliance (see Smith, 2018; 
Duncan, 2017; Ferguson, 2009; Plunkett, 2018). In doing so, the authors have demonstrated how language can be subtly reshaped and employed as a way of labelling behaviour exhibited by either social worker or parent. This practice has, in effect, highlighted the fact that 'disguised compliance' is awkward by nature and open to re-interpretation.

Although 'disguised compliance' presents as a term which can identify concerning behaviour, its application fails to recognize that families labelled as such will always struggle to attain the professional's desired position, leaving them in a no-win situation. If parents comply with objectives they will be treated with caution, if they resist they will be treated with suspicion. Furthermore, our analysis shows that when social workers adopt the term, they are not actually dealing with disguised compliance but rather 'disguised resistance'. This finding does not mean that the term 'disguised compliance' should be abandoned and replaced with the concept of 'disguised resistance', but rather used to highlight that language in social work is significant- it can have powerful consequences for families if used uncritically. Instead of seeking, therefore, to label lack of engagement, practitioners should perhaps ask: What risk discourses and practices have led to this situation? Where do they come from? Where do they lead to? And who do they affect? In doing so, sociological understandings of power could then be properly explored and practitioners could focus on building relationships based on recognition, respect and reciprocity.

\section{Conclusion}

It has been widely acknowledged that the current social work context can have serious ramifications for families involved with social care intervention (Featherstone et al. 2014; 2016; Smithson and Gibson, 2016; Turney, 2012). This article has contributed a different angle to the debate by exploring the impact language can have on social work practice and how affective currents can influence the ways in which words are generated. 
By critically analysing a wide range of texts through an affective framing lens we have been able to document the impact 'disguised compliance' has had on the social work community. A factor that underpins all the accounts we have read is that authors who use the term do so because they are trying to make sense of situations that practitioners have encountered. The act of making sense of experiences does not just involve a process of interpreting events but offers rationalizations of how such events can be dealt with in future (Gabriel, 2015). An event, such as a death, an accident or a failure, can very well 'make sense' in a rational manner, if it can be linked to a cause and labelled as 'disguised compliance'. However, accepting something intellectually, is very different from accepting the emotional consequence it can have for the families who are involved with social care.

These messages have important implications for practitioners and the wider social work community because they highlight how popular concepts can influence intra-agency practice and subsequently contribute to the belief that treating parents with suspicion will improve social workers' detective skills and, in turn, prevent children from being abused. As the findings from this article demonstrate, the concept of disguised compliance needs to be treated with caution because it does not predict risk nor does it address it. Instead, it locks both social worker and parent into dead-end positions that not only fail to recognise the riskaverse thinking that is at play but also the power imbalances present in the relationship.

This form of situated activity also conceals the role of language and the power that language has in concealing the fears professionals have in relation to working with risk. As Hall et al. (2010) argued, practice is mediated by language and interaction and this leads to inferences being made about what to do, to what extent and what should happen next. Popular terms can act as powerful signifiers which can socialize workers into adopting particular stances within practice which in turn negatively affect dynamics between practitioners and the families they work with. In these kinds of scenarios, the parent then 
becomes the problem rather than the practitioner, primed to interpret the behaviour of parents who do not keep appointments but do tidy the house as exhibiting 'disguised compliance'.

\section{Funding}

No funding was received to support this study

\section{Conflict of Interest}

The authors declare that there is no conflict of interest

\section{Acknowledgements}

We would like to thank the anonymous reviewers for their comments and also Sue White and Robin Sen for their contributions prior to submission.

\section{References}

Brandon, M. et al.(2008) Analysing child deaths and serious injury through abuse and neglect: what can we learn? A biennial analysis of serious case reviews 2003-2005. London: Department for Education and Skills (DfES).

Burr, V. (2003) Social Constructionism. London: Routledge.

Crossley, S. Leigh, J. (2016) The 'Troubled' Case of Rotherham. Critical and Radical Social Work. 5(1), 23-40. doi:10.1332/204986016X14798319535531

Duncan, A (2017) Serious Case Review on W Family. Greenwich Safeguarding Children Board. https://www.royalgreenwich.gov.uk/safeguardingchildrenboard/info/200131/greenwic h_safeguarding_children_board/93/serious_case_reviews_scrs 
Easton, M. (2009) Baby Peter and the Uncertainty Principle http://www.bbc.co.uk/blogs/thereporters/markeaston/2009/08/baby_peter_and the un certainty.html

Featherstone, B. White, S. Morris, K. (2014) Marriage made in Hell: Early intervention meets child protection. British Journal of Social Work. 44 (7): 1735-1749.

Ferguson, H. (2004) Protecting children in time. Hampshire: Palgrave Macmillan.

Ferguson, H. (2009) Performing child protection: home visiting, movement and the struggle to reach the abused child. Child and Family Social Work. 14, 471-480.

Gibson, M. (2015). Shame and guilt in child protection social work: New interpretations and opportunities for practice. Child \& Family Social Work, 20(3), 333-343. doi: $10.1111 /$ cfs. 12081

Hart, P. (2017) 'Disguised Compliance - Or Undisguised Nonsense?'. Family Law Week. http://www.familylawweek.co.uk/site.aspx?i=ed177164

Hall, A. (2017) Safeguarding Children in Schools https://www.safeguardinginschools.co.uk Jones, R. (2014) The Story of Baby P: Setting the record straight. Bristol: Policy Press Keddell, E. (2014)

Kettle, M. Jackson, S. (2017) Revisiting the Rule of Optimism, The British Journal of Social Work, 47, 6, 1624-1640,

Leigh, J. (2017) Blame, Culture and Child Protection. London: Palgrave MacMillan. Lonne, B. and N. Parton (2014). "Portrayals of Child Abuse Scandals in the Media in Australia and England: Impacts on Practice, Policy, and Systems: Most media coverage distorts the public understandings of the nature of child maltreatment." Child Abuse \& Neglect 38(5): 822-836.

NSPCC (2014) Disguised compliance: learning from case reviews: Summary of risk factors and learning for improved practice around families and disguised compliance 
https://www.nspcc.org.uk/preventing-abuse/child-protection-system/case-

reviews/learning/disguised-compliance/

Plunkett, A. (2018) Local Safeguarding Children Board, Executive Summary Report Serious Case Review, Children F,G,H. Published by the NSPCC On behalf of an unnamed local safeguarding children board https://safeguarding.network/wpcontent/uploads/2018/10/2018-Anonymous-SCR-Children-FGH.pdf

Potter, J. and Wetherell, M. (1987) Discourse and social psychology: Beyond attitudes and behaviour. London: Sage.

Reder, P. Duncan, S. Gray, M. (1993) Beyond Blame: Child Abuse Tragedies Revisited. London: Taylor and Francis.

Scourfield, J., \& Welsh, I. (2003). Risk, reflexivity and social control in child protection: new times or same old story? Critical Social Policy, 23(3), 398-420.

Shemmings, D., Shemmings, Y., \& Cook, A. (2012). Gaining the trust of 'highly resistant' families: Insights from attachment theory and research. Child \& Family Social Work, 17(2), 130-137. doi: 10.1111/j.1365-2206.2012.00834.x

Shoesmith, S. (2016) Learning from Baby P: The politics of blame, fear and denial. London: Jessica Kingsley Publishers.

Sidebotham, P. Brandon, M., Bailey, S., Belderson, P., Dodsworth, J., Garstang, J., Harrison, E., Retzer, A., Sorensen, P. (2016) Pathways to harm, pathways to protection: a triennial analysis of serious case reviews 2011 to 2014. Department for Education. London: HMSO.

Smith, F. (2018) Serious Case Review Child 'M'. City of London \& Hackney Safeguarding Children Board. http://www.chscb.org.uk/wp-content/uploads/2018/03/CHSCBSCR-Child-M-Report.pdf 
Smithson, R. and Gibson, M. (2016) Less than human: a qualitative study into the experience of parents involved in the child protection system. Child \& Family Social Work, 'Online First' Published 4th February 2016 [Available from: DOI: 10.1111/cfs.12270].

Turnell, A. (2006). Constructive child protection practice: An oxymoron or news of difference? Journal of systemic therapies, 25(2), 3 - 12.

Turney, D. (2012). A relationship-based approach to engaging involuntary clients: The contribution of recognition theory. Child \& Family Social Work, 17(2), 149-159. doi: $10.1111 / \mathrm{j} .1365-2206.2012 .00830 . x$

Von Scheve, C., Zink, V., Ismer, S. (2014) The Blame Game: Economic Crisis Responsibility, Discourse and Affective Framings. Sociology. 50, 4, 635-651.

Warner, J. (2013). Social work, class politics and risk in the moral panic over Baby P. Health, Risk \& Society, 15(3), 217-233. doi:10.1080/13698575.2013.776018

Wetherell M (2012) Affect and Emotion. London: Sage.

Wilkins, D. (2017) 'We need to rethink our approach to disguised compliance'. Community Care. http://www.communitycare.co.uk/2017/03/16/need-rethink-approach-disguisedcompliance/ 